\title{
Extreme intra-clutch egg size dimorphism is not coupled with corresponding differences in antioxidant capacity and stable isotopes between eggs
}

\author{
Maud Poisbleau ${ }^{\mathrm{a}, *}$, Michaël Beaulieu $^{\mathrm{b}}$, Nina Dehnhard ${ }^{\mathrm{a}}$, Laurent Demongin ${ }^{\mathrm{a}}$, Gilles Lepoint ${ }^{\mathrm{c}}$, \\ Nicolas Sturaro ${ }^{\mathrm{c}}$, Marcel Eens ${ }^{\text {a }}$ \\ a Behavioural Ecology \&' Ecophysiology Group, Department of Biology, University of Antwerp, Campus Drie Eiken, Universiteitsplein 1, 2610 Antwerp (Wilrijk), Belgium \\ b Zoological Institute and Museum, University of Greifswald, Johann-Sebastian Bach Str. 11/12, 17489 Greifswald, Germany \\ c Laboratory of Oceanology, FOCUS UR, University of Liège, B6C, 4000 Liège, Sart Tilman, Belgium
}

\section{A R T I C L E I N F O}

\section{Article history:}

Received 12 July 2016

Received in revised form 3 December 2016

Accepted 28 December 2016

Available online 04 January 2017

\section{Keywords:}

Antioxidant capacity

Crested penguins

Female condition

Maternal transfer

Oxidative status

Stable isotope

\begin{abstract}
A B S T R A C T
Oviparous females need to allocate resources optimally to their eggs in order to maximize their fitness. Among these resources, dietary antioxidants, acquired by females and transferred to the eggs during egg formation, can greatly affect the development and survival of the embryo and chick. In crested penguins, incubation starts after the second and last egg is laid and, as opposed to many other bird species, this egg hatches first, thereby enhancing the survival of the chick. Here, we assessed whether antioxidant and isotopic composition could underlie these differences between eggs within clutches of southern rockhopper penguins (Eudyptes chrysocome chrysocome). The second-laid egg had higher total antioxidant capacity than the first-laid egg, although this was not due to higher antioxidant concentration but to its higher mass. This suggests that resources are allocated by females at a constant rate in both eggs within clutches. Accordingly, we found a strong correlation for isotopic compositions between eggs suggesting that resources were allocated similarly to each egg within the clutch. Overall, we found little evidence for a significant role of antioxidant and isotopic compositions to explain differences in terms of embryo/chick development between eggs in crested penguins. However, since our results suggest a constant rate of antioxidant transfer from females to eggs, limiting the mass of the first-laid egg might represent a strategy for females to spare antioxidant defences and preserve self-maintenance.
\end{abstract}

(C) 2017 Elsevier Inc. All rights reserved.

\section{Introduction}

By varying the transfer of antioxidant resources to their eggs (Royle et al., 2003), female birds can strongly affect the development and survival of their offspring (Wilson, 1997; Møller et al., 2008; Deeming and Pike, 2013). However, as these antioxidant resources are of dietary origin and are therefore limited (Royle et al., 2003), their transfer to the eggs may be costly and deleterious to laying females in terms of selfmaintenance (energy limitation hypothesis; Roff, 1992; Stearns, 1992; Zera and Harshman, 2001). Depositing antioxidants into eggs may indeed decrease the females' own antioxidant defences and increase their levels of oxidative damage (Morales et al., 2008; Giordano et al., 2015). This is likely to explain why females feeding in habitats with low food availability, or having a poor nutrient status, a poor body condition, or low antioxidant defences decrease the allocation of antioxidants (as well as other nutrients) to their eggs (Hargitai et al., 2006; Navara et al., 2006; Isaksson et al., 2008). Consequently, laying females

\footnotetext{
* Corresponding author.

E-mail address: maud.poisbleau@gmail.com (M. Poisbleau).
}

may have to modulate the total antioxidant transfer to their clutch and/ or its distribution within this clutch in relation to their own condition. This suggests the existence of an interplay between female feeding behaviour, transfer of resources to their eggs, their own antioxidant status, and that of their eggs.

Stable isotope analysis can provide insights on the effects of variation in resource availability on antioxidant allocation. The isotopic composition of an animal's tissue is indeed directly linked to that of its diet. Isotope ratios may vary spatially and reflect the habitat in which animals feed, in addition nitrogen isotope ratios generally increase from prey to consumer tissue and may reflect trophic levels (see Cherel et al., 2007 and references therein). Stable isotope analysis therefore represents an indirect method to assess foraging strategies, which can be used to determine the relative importance of feeding sources (Gauthier et al., 2003). For instance, penguins predominantly feeding on krill (with low $\delta{ }^{13} \mathrm{C}$ and $\delta{ }^{15} \mathrm{~N}$ values) show low isotope values compared to penguins predominantly feeding on fish (with high $\delta^{13} \mathrm{C}$ and $\delta{ }^{15} \mathrm{~N}$ values) (Polito et al., 2011; Dehnhard et al., 2016). Krill also contains higher levels of lipophilic antioxidants (mostly astaxanthin) than fish (Tou et al., 2007). Therefore, markers of antioxidant capacity 
and isotopic composition can correlate in seabirds' blood and eggs (Hipfner et al., 2010; García-Tarrasón et al., 2014; Beaulieu et al., 2015).

Crested penguins (genus Eudyptes) present a unique extreme intraclutch egg size dimorphism, with the first-laid egg (the A-egg) being 55-75\% the size of the second-laid egg (the B-egg) (Warham, 1975; Demongin et al., 2010). In the typical two-egg nests of southern rockhopper penguins (Eudyptes chrysocome chrysocome), the hatching success is similar between A- and B-eggs, but A-eggs take longer to hatch and produce smaller chicks that usually do not survive due to almost obligatory brood reduction (St. Clair, 1996; Poisbleau et al., 2008). This disadvantage of A-eggs relative to B-eggs in terms of embryonic development and chick survival becomes apparent only when both eggs are incubated together, but not if A-eggs are incubated alone. In contrast, embryonic development and chick survival remain constant in B-eggs irrespective of incubation conditions (Poisbleau et al., 2008). This suggests that A-eggs are more sensitive to incubation conditions than Beggs. Differences in the composition of both eggs may contribute to these differences in sensitivity, and low levels of antioxidant defences in A-eggs may be related to a high sensitivity to incubation conditions resulting in a slow(er) embryonic development. For instance, interspecific comparisons in birds have shown that the speed of embryonic development increases in relation to the quantity of maternal antioxidants transferred into the egg (Deeming and Pike, 2013). If this pattern holds true also at the intra-clutch scale, we could expect A-eggs to have a lower antioxidant capacity than B-eggs in rockhopper penguins, which might contribute to their slower development (Prediction 1).

Southern rockhopper penguins are considered as typical capital breeders (Jönsson, 1997; Meijer and Drent, 1999) with females acquiring body reserves before and during migration to breeding sites, fasting and relying solely on body reserves during egg production. Under these assumptions, we predict that the oxidative status and isotopic compositions of females should be directly reflected in the oxidative status and the isotopic compositions of their eggs (Prediction 2).

Nevertheless, we observed that females return to the colony about 18 days before clutch initiation (Poisbleau et al., 2015) while egg production lasts about 23 days, with A-egg production starting four days prior to B-eggs (Grau, 1982; Crossin et al., 2010). We therefore assume that females are still likely to acquire food for direct (at least A-) egg production while migrating. The relative contribution of the exogenous (acquired at the time of egg production during migration) and endogenous (acquired away from the breeding site) nutrients into eggs should therefore be reflected by a difference in egg isotopic composition (see Hobson et al., 2015; Ramírez et al., 2015 for examples of studies using this effective and precise method for tracing nutrient allocation into eggs). Under these conditions, we expect a difference in isotopic composition between A- and B-eggs if both endogenous and exogenous nutrients are used for clutch production (with a higher contribution of exogenous resources in A-eggs), but no difference in isotopic composition between eggs if only endogenous reserves are mobilised (Prediction 3).

Finally, we expect females limited in their ability to invest in reproduction (because of a poor nutritional state) to lay more dimorphic clutches, thus favouring the survival of at least one (the B-) egg/chick. We therefore expected a relationship between female condition (body mass, oxidative status or isotopic composition) and intra-clutch differences in terms of egg quality (mass, antioxidant status and isotopic composition; Prediction 4).

\section{Materials and methods}

\subsection{Study site and birds}

The study was carried out during the austral summer 2012 on southern rockhopper penguins breeding at the "Settlement Colony" $\left(51^{\circ} 43^{\prime} \mathrm{S}\right.$, $61^{\circ} 17^{\prime} \mathrm{W}$ ) on New Island, Falkland/Malvinas Islands. The breeding biology of this population that held about 8300 pairs in 2012 has been described previously in Poisbleau et al. (2008). The birds mainly breed in open rocky areas fringed by tussac grass Poa flabellata. Males arrive in the colony first (early October) and establish nest sites. Females arrive a few days later, for pairing and copulation in late October/early November. Egg laying is very synchronised within this population, taking place in less than two weeks (see Poisbleau et al., 2008).

Since 2006, we have gradually marked 461 randomly-chosen adult females in the colony, equipping them with 23-mm long glass-encapsulated electronic transponders (TIRIS, Texas Instruments, USA). We determined the sex of birds through bill measurements within pairs, with males typically having larger bills than females (Poisbleau et al., 2010).

\subsection{Adult manipulation}

During the 2012 laying period, we visited the study site daily to follow egg laying. We randomly chose 40 marked females, which were homogeneously distributed within the study site and the laying period. They were captured on the day they laid their A-egg (i.e. date of laying onset). After covering their head with a hood to minimize stress, we collected up to one $\mathrm{ml}$ of blood from the brachial vein, using a 23-gauge needle and heparinized syringe. Blood samples, which were collected within three minutes after capture, were stored on ice while still in the colony, and were centrifuged within three hours. Red blood cells and plasma samples were stored at $-20{ }^{\circ} \mathrm{C}$ in separated $1.5-\mathrm{ml}$ Eppendorf tubes until analysis.

We weighed each female to the nearest $20 \mathrm{~g}$ with an electronic balance following Poisbleau et al. (2010). Since indices of body condition may not be more precise than body mass itself (Schamber et al., 2009), we did not control for structural size in further analyses.

Table 1

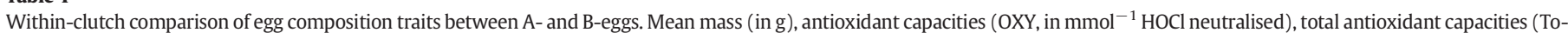

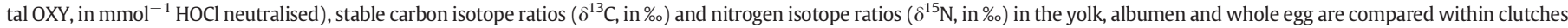
between A- and B-eggs using paired $t$-tests and paired correlations.

\begin{tabular}{|c|c|c|c|c|c|c|}
\hline \multirow[b]{2}{*}{ Trait } & \multicolumn{2}{|l|}{ Mean $\pm \mathrm{SE}$} & \multicolumn{2}{|c|}{ Paired correlation } & \multicolumn{2}{|c|}{ Paired $t$-test } \\
\hline & A-egg & B-egg & $\mathrm{r}$ & $P$-value & $\mathrm{t}$ & $P$-value \\
\hline Yolk mass & $19.4 \pm 0.5$ & $22.0 \pm 0.3$ & 0.643 & $<0.001$ & 7.357 & $<0.001$ \\
\hline Albumen mass & $64.1 \pm 1.1$ & $81.1 \pm 1.2$ & 0.839 & $<\mathbf{0 . 0 0 1}$ & 26.29 & $<\mathbf{0 . 0 0 1}$ \\
\hline Egg mass & $95.8 \pm 1.6$ & $118.4 \pm 1.4$ & 0.834 & $<0.001$ & 25.74 & $<0.001$ \\
\hline $\mathrm{OXY}_{\text {Yolk }}$ & $2726 \pm 73$ & $2705 \pm 90$ & -0.184 & 0.256 & -0.169 & 0.866 \\
\hline $\mathrm{OXY}_{\text {Albumen }}$ & $349 \pm 6$ & $349 \pm 6$ & 0.140 & 0.388 & -0.008 & 0.994 \\
\hline Total OXY Yolk & $26.10^{6} \pm 10^{6}$ & $30.10^{6} \pm 10^{6}$ & 0.182 & 0.261 & 2.497 & 0.017 \\
\hline Total $\mathrm{OXY}_{\text {Albumen }}$ & $11.10^{6} \pm 0.3 .10^{6}$ & $14.10^{6} \pm 0.3 .10^{6}$ & 0.466 & 0.002 & 10.23 & $<0.001$ \\
\hline Total OXY & $37.10^{6} \pm 10^{6}$ & $44.10^{6} \pm 10^{6}$ & 0.212 & 0.188 & 4.260 & $<0.001$ \\
\hline$\delta^{13} \mathrm{C}_{\text {Yolk }}$ & $-19.4 \pm 0.1$ & $-19.4 \pm 0.1$ & 0.912 & $<0.001$ & -0.134 & 0.894 \\
\hline$\delta^{13} \mathrm{C}_{\text {Albumen }}$ & $-19.6 \pm 0.1$ & $-19.4 \pm 0.1$ & 0.993 & $<\mathbf{0 . 0 0 1}$ & 15.01 & $<0.001$ \\
\hline$\delta^{15} \mathrm{~N}_{\text {Yolk }}$ & $14.1 \pm 0.1$ & $14.3 \pm 0.2$ & 0.927 & $<\mathbf{0 . 0 0 1}$ & 2.998 & 0.005 \\
\hline$\delta^{15} \mathrm{~N}_{\text {Albumen }}$ & $15.3 \pm 0.2$ & $15.4 \pm 0.2$ & 0.985 & $<0.001$ & 3.571 & 0.001 \\
\hline
\end{tabular}




\subsection{Egg collection and preparation}

Once A-eggs were detected in the 40 study nests, we collected and replaced them with foster eggs (i.e. eggs of close size lost by their original parents and found outside a nest) in order to minimize potential effects of egg removal on birds' physiology and behaviour, and thus B-egg composition. Afterwards, we checked nests daily until the laying of Beggs. We collected B-eggs as soon as they were detected and also replaced them with foster eggs. As incubation in rockhopper penguins typically starts at clutch completion (Williams, 1995), A-eggs were not incubated at all and B-eggs were incubated no longer than $24 \mathrm{~h}$ before being collected. We therefore assumed that embryo development (if any) was very preliminary and similar between eggs. Accordingly, no embryo development was observed during the preparation of the collected eggs. In total, we collected 40 entire clutches. After collection, we weighed the eggs to the nearest $0.1 \mathrm{~g}$ using a digital balance and froze them whole at $-20^{\circ} \mathrm{C}$.

We examined quantitatively and qualitatively the egg yolk and albumen, as both egg components appear important for chick development and survival (Ferrari et al., 2006; Bonisoli Alquati et al., 2007). The same method was used to prepare all frozen eggs for subsequent analyses (Poisbleau et al., 2009, 2011a, 2011b, 2011c). While the egg was still frozen, we removed its shell before cutting few millimetres off its pointed end to collect a small quantity of frozen albumen (between the section and yolk) into a 1.5-ml Eppendorf tube. Then, we separated the yolk from the albumen by taking advantage that albumen thaws more quickly than yolk. Using a digital balance $( \pm 0.1 \mathrm{~g})$, we recorded shell and yolk mass and calculated albumen mass by subtracting shell and yolk masses from total egg mass. Since composition is not homogeneous within the yolk (Lipar et al., 1999; Hackl et al., 2003), we carefully homogenized the yolk by swirling it with a mini-spatula. A small quantity of each homogenized yolk (representative of the whole yolk) was transferred to a 1.5-ml Eppendorf tube. Yolk and albumen samples were stored at $-20^{\circ} \mathrm{C}$ until analysis.

\subsection{Oxidative status analyses}

To measure markers of oxidative status, we employed two tests that have already been successfully used on birds' plasma and egg components (e.g. Costantini, 2010). For plasma samples, we used the OXY-Adsorbent (Diacron International, Grosseto, Italy) and the d-ROMs tests, and for egg samples we used the OXY-Adsorbent test. The OXY-Adsorbent test measures the total non-enzymatic antioxidant capacity of biological samples (expressed in $\mathrm{mmol}$ of $\mathrm{HClO}$ neutralised), while the $\mathrm{d}$ ROM test measures the concentration of hydroperoxides (expressed in mg $\mathrm{H}_{2} \mathrm{O}_{2} \cdot \mathrm{dl}^{-1}$ ), a class of reactive oxygen metabolites (ROM) resulting from the action of reactive oxygen species (ROS) on biomolecules (Beaulieu et al., 2010a; Costantini, 2016). Prior to measurements, yolk samples were diluted in ultrapure water ( $c a .0 .2 \mathrm{~g}$ in $2 \mathrm{ml}$ of ultrapure water) with eight glass beads, and homogenised using both a vortex and a sonicator. For OXY measurements, yolk, albumen and plasma samples were additionally diluted ( $2 \mu \mathrm{l}$ of sample in $198 \mu$ of ultrapure water), and $5 \mu \mathrm{l}$ of the resulting solutions were then used for spectrophotometric measurements. OXY values in diluted yolks were thereafter corrected with dilution factors to obtain values in original yolks. ROM measurements were conducted by using $4 \mu \mathrm{l}$ of undiluted plasma samples. Absorbance readings were conducted at $510 \mathrm{~nm}$ (for details on procedures, see Beaulieu et al., 2010b). For OXY measurements, intraand inter-assay coefficients of variation were, respectively, 6 and 14\% in plasma samples, 10 and 13\% in yolk samples, and 5 and 9\% in albumen samples. For ROM measurements in plasma samples, intra- and interassay coefficients of variation were 5 and $6 \%$, respectively.

Because A- and B-eggs vary in size and mass in southern rockhopper penguins (Poisbleau et al., 2008), we also calculated the total antioxidant capacity (hereafter called Total OXY) for the whole yolk and for the whole albumen of each egg, by multiplying OXY values (in mmol

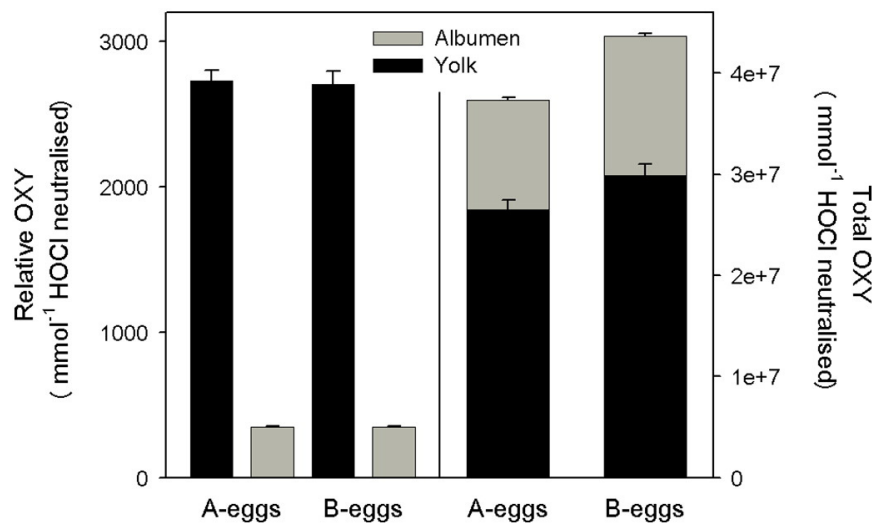

Fig. 1. Egg antioxidant capacity in the yolk and albumen of A- and B-eggs presented as concentrations (OXY) in the left frame, and as cumulative total amounts (Total OXY) in the right frame. Mean \pm SE.

of $\mathrm{HOCl}$ neutralised) with the mass (in grams) of each component (Total OXY $=\mathrm{OXY} \times$ mass). This enabled us to calculate the total antioxidant capacity for each egg as a whole (Total $\mathrm{OXY}_{\mathrm{Egg}}=$ Total $\mathrm{OXY}_{\text {Yolk }}+$ Total $\left.\mathrm{OXY}_{\text {Albumen }}\right)$, which was used as a proxy for the reproductive investment of females in terms of antioxidant transfer to their eggs. We also estimated the total amount of antioxidants that females had already deposited in their clutch while laying A-eggs (i.e. when blood was collected), by adding the total antioxidant capacities of Aegg yolk, B-egg yolk and A-egg albumen (Total OXYClutch at bleeding $=$ Total OXYA-Egg + Total OXYB-Yolk; B-egg albumen was not considered here since its synthesis occurs after A-egg laying; Ancel et al., 2013). The calculation of Total $\mathrm{OXY}_{\text {Clutch at bleeding }}$ combined with oxidative measurements in female blood enabled us to examine whether antioxidant transfer to the eggs compromised the oxidative status of females at that time.

\subsection{Stable isotope analyses}

Red blood cells, yolk and albumen samples were dried at $60{ }^{\circ} \mathrm{C}$, ground to a fine powder and homogenised. Due to the yolks' high lipid content, which leads to depleted ${ }^{13} \mathrm{C}$ (Oppel et al., 2010), yolk samples were divided into two subsamples, one of which was delipidated. We followed the methodology of Ehrich et al. (2011) and added a 2:1 chloroform-methanol mixture to the dried, powdered yolk. After $15 \mathrm{~min}$ on a reciprocating lab shaker, samples were centrifuged for $10 \mathrm{~min}$ and the supernatant removed. This procedure was repeated

\section{Table 2}

Results of paired correlations between yolk and albumen traits within A- and B-eggs. Mass (in g), antioxidant capacities (OXY, in $\mathrm{mmol}^{-1} \mathrm{HOCl}$ neutralised), total antioxidant capacities (Total OXY, in $\mathrm{mmol}^{-1} \mathrm{HOCl}$ neutralised), stable carbon isotope ratios $\left(\delta^{13} \mathrm{C}\right.$, in \% $)$ and nitrogen isotope ratios $\left(\delta^{15} \mathrm{~N}\right.$, in \%o).

\begin{tabular}{lll}
\hline & Paired correlation & \\
\cline { 2 - 3 } Trait & $\mathrm{r}$ & $P$-value \\
\hline A-eggs & & \\
Mass & $\mathbf{0 . 6 0 1}$ & $<\mathbf{0 . 0 0 1}$ \\
OXY & 0.071 & 0.664 \\
Total OXY & $\mathbf{0 . 5 1 8}$ & $\mathbf{0 . 0 0 1}$ \\
$\delta^{13} \mathrm{C}_{\text {Yolk with lipids }}$ & $\mathbf{0 . 9 3 4}$ & $<\mathbf{0 . 0 0 1}$ \\
$\delta^{13} \mathrm{C}$ & $\mathbf{0 . 9 2 8}$ & $<\mathbf{0 . 0 0 1}$ \\
$\delta^{15} \mathrm{~N}$ & $\mathbf{0 . 9 1 4}$ & $<\mathbf{0 . 0 0 1}$ \\
B-eggs & & \\
Mass & $\mathbf{0 . 3 1 6}$ & $\mathbf{0 . 0 4 7}$ \\
OXY & -0.014 & 0.933 \\
Total OXY & 0.080 & 0.624 \\
$\delta^{13} \mathrm{C}_{\text {Yolk with lipids }}$ & $\mathbf{0 . 9 5 0}$ & $<\mathbf{0 . 0 0 1}$ \\
$\delta^{13} \mathrm{C}$ & $\mathbf{0 . 9 5 2}$ & $<\mathbf{0 . 0 0 1}$ \\
$\delta^{15} \mathrm{~N}$ & $\mathbf{0 . 9 5 9}$ & $<\mathbf{0 . 0 0 1}$ \\
& &
\end{tabular}


Table 3

Results of general linear models (GLMs) examining the effects of laying date (in Julian date), female mass (in $\mathrm{g}$ ), female isotopic composition $\left(\delta^{13} \mathrm{C}_{\mathrm{Female}}\right.$, in \%o), female antioxidant capacity $\left(\mathrm{OXY}_{\mathrm{Female}}\right.$, in $\mathrm{mmol}^{-1} \mathrm{HOCl}$ neutralised) and female oxidative damage ( $\mathrm{ROM}_{\mathrm{Female}}$, in $\mathrm{mg} \mathrm{H}_{2} \mathrm{O}_{2} \mathrm{dl}^{-1}$ ) on the yolk and albumen antioxidant capacities (OXY Yolk and $\mathrm{OXY}_{\text {Albumen, }}$, in $\mathrm{mmol}^{-1} \mathrm{HOCl}$ neutralised) for A- and B-eggs. As $\delta^{13} \mathrm{C}_{\mathrm{Female}}$ and $\delta$ ${ }^{15} \mathrm{~N}_{\text {Female }}$ were correlated, we included these two variables in two different GLMs that gave similar results. We here present only the results for the GLM with $\delta^{13} \mathrm{C}_{\text {Female }}$.

\begin{tabular}{|c|c|c|c|c|}
\hline & \multicolumn{2}{|c|}{$\mathrm{OXY}_{\text {Yolk }}$} & \multicolumn{2}{|c|}{$\mathrm{OXY}_{\text {Albumen }}$} \\
\hline & $F_{1,34}$ & $p$ & $F_{1,34}$ & $p$ \\
\hline \multicolumn{5}{|l|}{ A-eggs } \\
\hline Laying date & 0.962 & 0.334 & 0.002 & 0.967 \\
\hline Female mass & 0.250 & 0.620 & 0.951 & 0.336 \\
\hline$\delta^{13} \mathrm{C}_{\mathrm{Female}}$ & 0.054 & 0.818 & 0.042 & 0.839 \\
\hline $\mathrm{OXY}_{\text {Female }}$ & 6.032 & 0.019 & 0.203 & 0.655 \\
\hline $\mathrm{ROM}_{\text {Female }}$ & 0.490 & 0.489 & 1.878 & 0.180 \\
\hline \multicolumn{5}{|l|}{ B-eggs } \\
\hline Laying date & 0.479 & 0.494 & 0.741 & 0.395 \\
\hline Female mass & 4.707 & 0.037 & 2.363 & 0.134 \\
\hline$\delta^{13} \mathrm{C}_{\mathrm{Female}}$ & 0.005 & 0.942 & 4.661 & 0.038 \\
\hline $\mathrm{OXY}_{\mathrm{Female}}$ & 0.200 & 0.657 & 0.952 & 0.336 \\
\hline ROM $_{\text {Female }}$ & 0.251 & 0.620 & 0.302 & 0.586 \\
\hline
\end{tabular}

until the supernatant was clear and colourless, and the delipidated yolk samples subsequently dried for $24 \mathrm{~h}$ under a fume hood. The untreated yolk subsample was used to measure carbon $\left(\delta^{13} \mathrm{C}\right)$ and nitrogen $\left(\delta^{15} \mathrm{~N}\right)$ isotopic compositions, whereas the delipidated yolk subsample was used to measure carbon $\left(\delta^{13} \mathrm{C}\right)$ isotopic composition. Measuring $\delta^{13} \mathrm{C}$ composition in both yolk subsamples allowed assessment of the direct effects of the presence of lipids. Red blood cells were not delipidated, as their low lipid content does not affect isotopic measurements in penguins (Cherel et al., 2005).

Stable isotope ratios of carbon $\left({ }^{13} \mathrm{C} /{ }^{12} \mathrm{C}\right)$ and nitrogen $\left({ }^{15} \mathrm{~N} /{ }^{14} \mathrm{~N}\right)$ were measured in $1 \mathrm{mg}$ aliquots, with an isotope ratio mass spectrometer (IsoPrime 100, Isoprime, UK) coupled in continuous flow to an elemental analyser (vario MICRO cube, Elementar, Germany). Isotope ratios were conventionally expressed in $\delta$ notation (Coplen, 2011) as parts per thousand (\%) deviation from the international standards Vienna Pee Dee Belemnite (carbon) and air (nitrogen), according to $\delta \mathrm{X}=\left[\left(\mathrm{R}_{\text {Sample }}-\mathrm{R}_{\text {Standard }}\right) / \mathrm{R}_{\text {Standard }}\right] \times 1000$, where $\mathrm{X}$ is ${ }^{13} \mathrm{C}$ or ${ }^{15} \mathrm{~N}$ and $\mathrm{R}$ is the corresponding ratio ${ }^{13} \mathrm{C} /{ }^{12} \mathrm{C}$ or ${ }^{15} \mathrm{~N} /{ }^{14} \mathrm{~N}$. Pure gases of $\mathrm{CO}_{2}$ and $\mathrm{N}_{2}$ were used and calibrated against certified reference materials, i.e. sucrose (IAEA-C6; $\delta^{13} \mathrm{C}=-10.8 \pm 0.5 \%$ ), ammonium sulphate
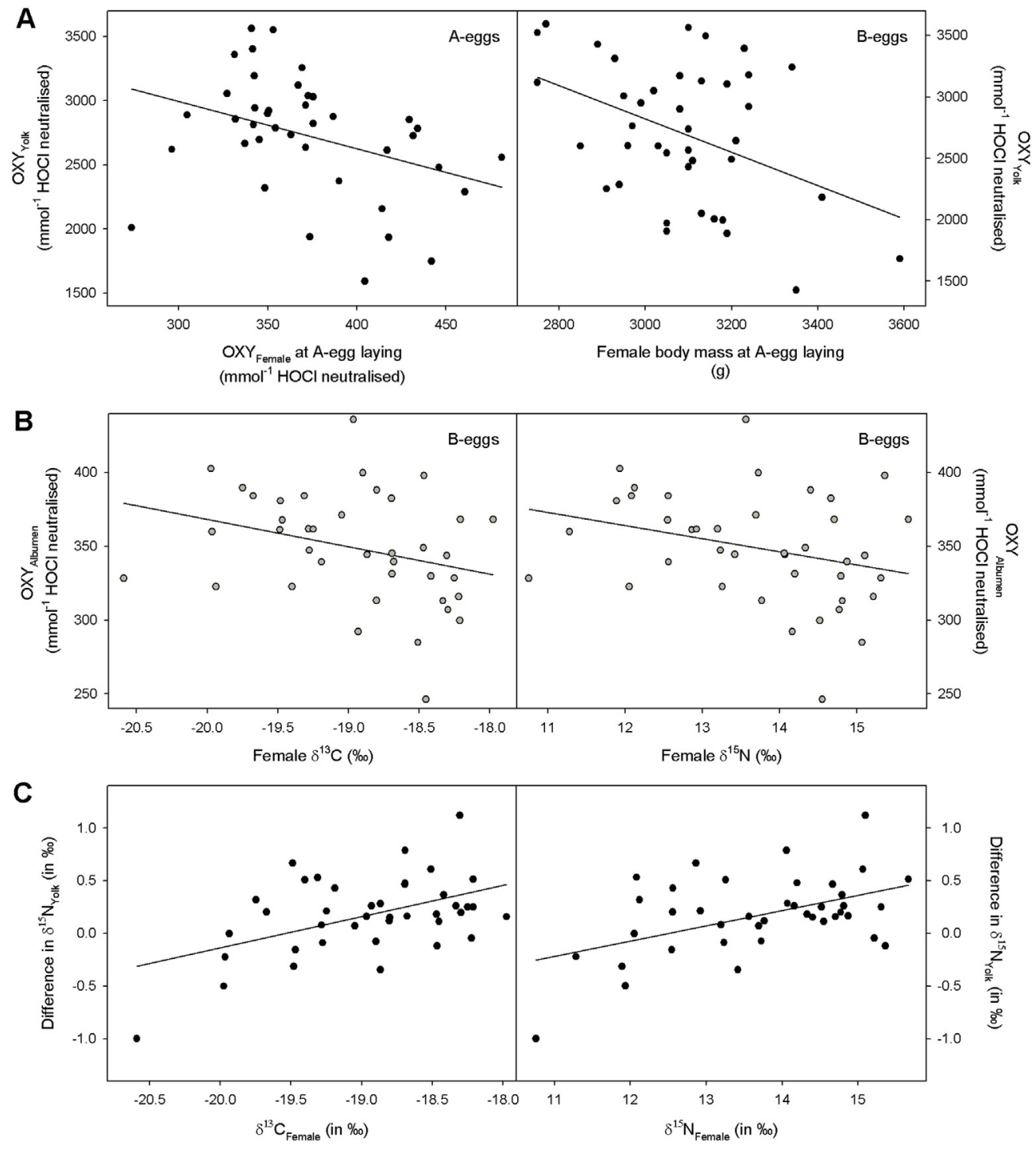

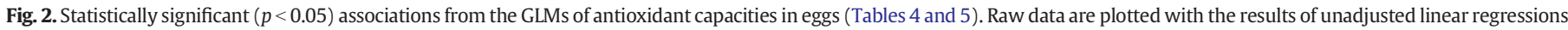

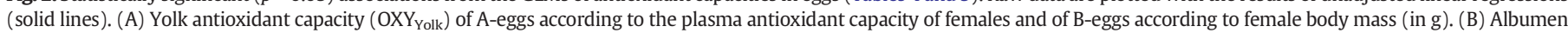
antioxidant capacity of B-eggs ( $\mathrm{OXY}_{\text {Albumen }}$ ) according to female $\delta^{13} \mathrm{C}$ and $\delta^{15} \mathrm{~N}$. (C) Intra-clutch difference (B-egg - A-egg) in $\delta^{15} \mathrm{~N}_{\text {Yolk }}$ according to $\delta^{13} \mathrm{C}_{\mathrm{Female}}$ and $\delta^{15} \mathrm{~N}_{\mathrm{Female}}$. 
(IAEA-N2; $\delta^{15} \mathrm{~N}=20.3 \pm 0.2 \%$ ). The analysis performance was assessed by procedural blanks, replicated samples and in-house standard (i.e. glycine). Analytical precision ( \pm standard deviation) on replicated samples equalled \pm 0.3 and $\pm 0.2 \%$ for $\delta^{13} \mathrm{C}$ and $\delta^{15} \mathrm{~N}$, respectively. Using allometric equations between body mass and carbon half-life in avian blood, carbon half-life in rockhopper penguin red blood cells was estimated to amount to 27 days (see Cherel et al., 2007). This means that two half-lives correspond to a $\sim 8$-week period during which most (75\%) blood carbon is renewed.

\subsection{Statistical analyses}

Statistical analyses were conducted in IBM SPSS Statistics 20 for Windows. Values are presented as means \pm standard errors. Sample size is consistently 40 females and 40 entire clutches (i.e. 40 A-eggs and 40 B-eggs) throughout the manuscript, including all tables and figures. Significant $p$-values $(<0.05)$ are marked in bold in tables.

We first explored correlations between female mass, oxidative status $\left(\mathrm{OXY}_{\mathrm{Female}}\right.$ and $\left.\mathrm{ROM}_{\text {Female }}\right)$ and isotope values $\left(\delta^{13} \mathrm{C}_{\mathrm{Female}}\right.$ or $\delta$ ${ }^{15} \mathrm{~N}_{\text {Female }}$ ) using Pearson correlations. We compared the mass, the oxidative status (OXY and Total OXY) and the isotope values $\left(\delta^{13} \mathrm{C}\right.$ or $\delta^{15} \mathrm{~N}$ ) between A- and B-eggs within clutches with paired $t$-tests and correlations. We conducted correlations between OXY values measured in the yolk and the albumen of each egg, and between female isotope values and those of their eggs.

We performed General Linear Model procedures (GLMs) to test whether (1) the oxidative status and isotopic composition of females were linked to the antioxidant capacity in the yolk ( $\left.\mathrm{OXY}_{\text {Yolk }}\right)$ and albumen ( $\left.\mathrm{OXY}_{\text {Albumen }}\right)$ of each of their eggs, (2) the total amount of antioxidants the females had already deposited in their clutch at A-egg laying (Total $\mathrm{OXY}_{\text {Clutch at bleeding }}$ ) correlated with their own oxidative status, and (3) the differences in terms of mass, oxidative status and isotope values between A- and B-eggs of the same clutch were related to the oxidative status and isotopic composition of females. In all GLMs, laying date and female body mass were added as covariates. As $\delta^{13} \mathrm{C}_{\mathrm{Female}}$ and $\delta^{15} \mathrm{~N}_{\text {Female }}$ were correlated, we ran separated GLMs for $\delta^{13} \mathrm{C}_{\mathrm{Female}}$

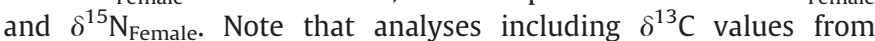
delipidated subsamples or from non-delipidated subsamples led to qualitatively similar results for all statistical tests except one. Therefore, we report only results for delipidated subsamples further below. We calculated the absolute difference ( trait $_{\mathrm{B} \text {-egg }}-$ trait $_{\mathrm{A} \text {-egg }}$ ) and the relative difference $\left(\left(\right.\right.$ trait $_{\mathrm{B} \text {-egg }}-$ trait $\left.\left._{\mathrm{A} \text {-egg }}\right) \times 100\right] /$ trait $\left._{\mathrm{A} \text {-egg }}\right)$ between eggs for their mass, oxidative status and isotope values. Considering absolute or relative egg differences led to similar statistical results. We therefore consider only absolute egg differences further below.

\section{Results}

\subsection{Female mass, oxidative status and isotopic composition}

$\mathrm{OXY}_{\mathrm{Female}}$ and ROM $\mathrm{Female}_{\mathrm{F}}$ were not correlated $(r=0.003, p=0.983)$, while $\delta^{13} \mathrm{C}_{\mathrm{Female}}$ and $\delta^{15} \mathrm{~N}_{\mathrm{Female}}$ were highly significantly and positively correlated $(r=0.944, p<0.001)$. None of these oxidative and isotope values were correlated to female body mass (all $p>0.382$ ). Moreover, oxidative and isotope values did not correlate with each other (all $p>0.642$ ).

\subsection{Egg antioxidant capacity}

\subsubsection{Antioxidant capacity}

Within clutches, $\mathrm{OXY}_{\text {Yolk }}$ and $\mathrm{OXY}$ Albumen did not covary, and did not differ between A- and B-eggs (Table 1; Fig. 1). Within eggs, $\mathrm{OXY}_{\text {Yolk }}$ did not covary with $\mathrm{OXY}_{\text {Albumen }}$ (Table 2).

The antioxidant capacity of females ( $\left.O X Y_{\text {Female }}\right)$ decreased when $\mathrm{OXY}_{\text {Yolk }}$ increased in A-eggs (Table 3; Fig. 2a), while their body mass decreased when $\mathrm{OXY}_{\text {Yolk }}$ increased in B-eggs (Table 3; Fig. 2a). Moreover,

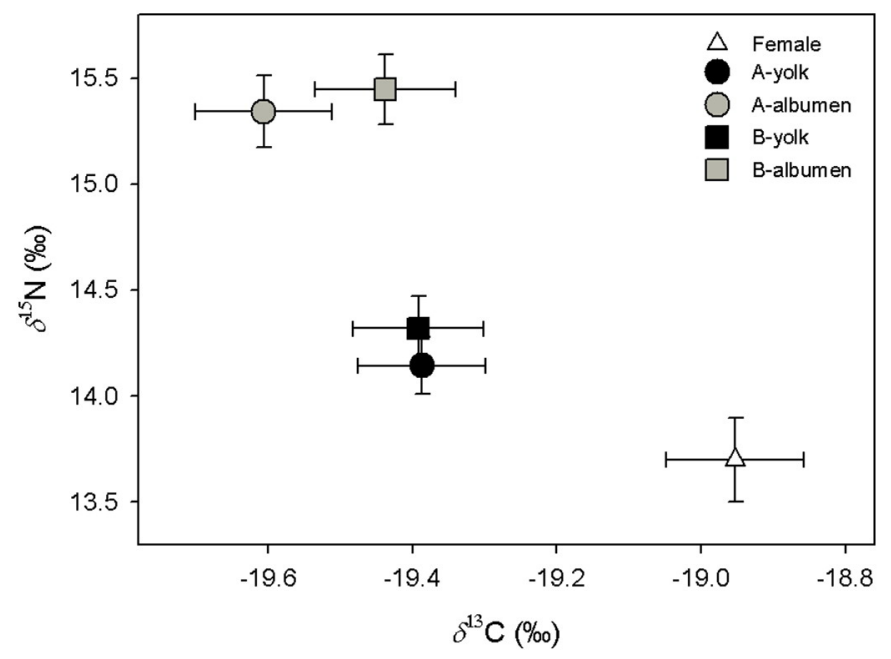

Fig. 3. Mean values ( $\pm \mathrm{SE}$ ) of $\delta^{13} \mathrm{C}$ and $\delta^{15} \mathrm{~N}$ in red blood cells of southern rockhopper penguin females (in white), and in the yolk (in black) and albumen (in grey) of their Aand B-eggs.

$\mathrm{OXY}_{\text {Albumen }}$ in B-eggs was negatively related to the isotope values of their mother (Table 3; Fig. 2b), and by extension to their own isotope values $\left(F_{1,34}=6.578, p=0.015\right.$ for $\delta^{13} C_{\text {Albumen }}$ and $F_{1,34}=7.181$, $p=0.011$ for $\left.\delta^{15} \mathrm{~N}_{\text {Albumen }}\right)$.

\subsubsection{Total antioxidant capacity}

Within clutches, Total $\mathrm{OXY}_{\text {Albumen }}$ was significantly positively correlated between A- and B-eggs (such a correlation was not observed in yolks and whole eggs), and B-eggs had higher Total OXY than A-eggs for the yolk, the albumen and the whole egg (Table 1; Fig. 1). Within eggs, Total $\mathrm{OXY}_{\text {Yolk }}$ and Total $\mathrm{OXY}_{\text {Albumen }}$ were significantly positively correlated in A-eggs (but not in B-eggs; Table 1).

\section{Table 4}

Results of the general linear models (GLMs) examining the effects of A-egg laying date (i.e. clutch initiation date and female capture date, in Julian date), female mass (in $\mathrm{g}$ ), female isotopic composition $\left(\delta^{13} \mathrm{C}_{\mathrm{Female}}\right.$, in \%), female antioxidant capacity ( $\mathrm{OXY}_{\mathrm{Female}}$, in $\mathrm{mmol}^{-1} \mathrm{HOCl}$ neutralised) and female oxidative damage ( $\mathrm{ROM}_{\mathrm{Female}}$, in $\mathrm{mg} \mathrm{H}_{2} \mathrm{O}_{2} \mathrm{dl}^{-1}$ ) on the difference (i.e. between $\mathrm{B}$ - and A-eggs) in mass (in g), oxidative capacity (OXY, in $\mathrm{mmol}^{-1} \mathrm{HOCl}$ neutralised) and isotope values (in \%) for the yolk and albumen. The same GLMs run with female $\delta^{15} \mathrm{~N}$ instead of female $\delta^{13} \mathrm{C}$ gave similar results.

\begin{tabular}{|c|c|c|c|c|}
\hline & \multicolumn{2}{|l|}{ Yolk } & \multicolumn{2}{|c|}{ Albumen } \\
\hline & $F_{1,34}$ & $p$ & $F_{1,34}$ & $p$ \\
\hline \multicolumn{5}{|l|}{ Mass difference } \\
\hline Laying date & 0.133 & 0.717 & 0.213 & 0.647 \\
\hline Female mass & 1.022 & 0.319 & 3.256 & 0.080 \\
\hline$\delta^{13} \mathrm{C}_{\mathrm{Female}}$ & 1.769 & 0.192 & 1.582 & 0.217 \\
\hline $\mathrm{OXY}_{\text {Female }}$ & 0.780 & 0.357 & 1.751 & 0.195 \\
\hline ROM $_{\text {Female }}$ & 1.033 & 0.317 & 0.153 & 0.698 \\
\hline \multicolumn{5}{|l|}{ OXY difference } \\
\hline Laying date & 1.278 & 0.266 & 0.381 & 0.541 \\
\hline Female mass & 1.336 & 0.256 & 3.898 & 0.057 \\
\hline$\delta^{13} \mathrm{C}_{\mathrm{Female}}$ & 0.039 & 0.845 & 2.390 & 0.131 \\
\hline $\mathrm{OXY}_{\text {Female }}$ & 3.108 & 0.087 & 0.191 & 0.665 \\
\hline $\mathrm{ROM}_{\text {Female }}$ & 0.573 & 0.454 & 2.319 & 0.137 \\
\hline \multicolumn{5}{|l|}{$\delta^{13} \mathrm{C}$ difference } \\
\hline Laying date & 0.060 & 0.808 & 0.010 & 0.919 \\
\hline Female mass & 0.205 & 0.654 & 0.042 & 0.838 \\
\hline$\delta^{13} \mathrm{C}_{\mathrm{Female}}$ & 0.100 & 0.754 & 1.441 & 0.238 \\
\hline $\mathrm{OXY}_{\mathrm{Female}}$ & 0.002 & 0.967 & 0.760 & 0.389 \\
\hline $\mathrm{ROM}_{\mathrm{Female}}$ & 1.917 & 0.175 & 0.556 & 0.461 \\
\hline \multicolumn{5}{|l|}{$\delta^{15} \mathrm{~N}$ difference } \\
\hline Laying date & 2.964 & 0.094 & 0.182 & 0.673 \\
\hline Female mass & 0.032 & 0.859 & 1.346 & 0.254 \\
\hline$\delta^{13} \mathrm{C}_{\mathrm{Female}}$ & 4.843 & 0.035 & 3.020 & 0.091 \\
\hline $\mathrm{OXY}_{\mathrm{Female}}$ & 0.030 & 0.865 & 0.087 & 0.770 \\
\hline $\mathrm{ROM}_{\mathrm{Female}}$ & 1.629 & 0.210 & 0.168 & 0.685 \\
\hline
\end{tabular}


Table 5

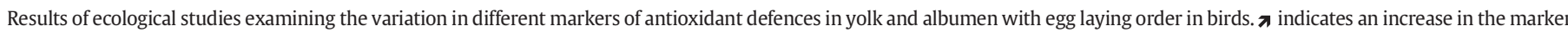
level within the laying sequence, $\boldsymbol{y}$ indicates a decrease and $\Rightarrow$ indicates no general trend within the laying sequence.

\begin{tabular}{|c|c|c|c|c|c|}
\hline Species & $\begin{array}{l}\text { Clutch } \\
\text { size }\end{array}$ & $\begin{array}{l}\text { Egg } \\
\text { component }\end{array}$ & $\begin{array}{l}\text { Marker of antioxidant } \\
\text { defences }\end{array}$ & Variation & Reference \\
\hline Perdix perdix & $1-20$ & Yolk & Carotenoids & $\Rightarrow$ & Cucco et al. (2007) \\
\hline \multirow[t]{2}{*}{ Columba livia } & \multirow[t]{2}{*}{$1-2$} & Albumen & OXY & $\pi$ & Costantini (2010) \\
\hline & & Yolk & OXY & $\Rightarrow$ & \\
\hline \multirow[t]{2}{*}{ Taeniopygia guttata } & \multirow[t]{2}{*}{$1-6$} & \multirow[t]{2}{*}{ Yolk } & Carotenoids & ע & Royle et al. (2003), Williamson et al. (2006), Griffith et al. (2011), Pariser et \\
\hline & & & Vitamin E & $y$ & al. $(2012)$ \\
\hline Ficedula albicollis & $1-5$ & Yolk & Carotenoids & $\Rightarrow \pi$ & Török et al. (2007) \\
\hline \multirow[t]{2}{*}{ Parus major } & \multirow[t]{2}{*}{$5-12$} & \multirow[t]{2}{*}{ Yolk } & Carotenoids & ע & \multirow[t]{2}{*}{ Hõrak et al. (2002) } \\
\hline & & & Vitamin E & $y$ & \\
\hline \multirow[t]{2}{*}{ Carpodacus mexicanus } & \multirow[t]{2}{*}{$2-6$} & \multirow[t]{2}{*}{ Yolk } & Carotenoids & $\Rightarrow$ & \multirow[t]{2}{*}{ Navara et al. (2006) } \\
\hline & & & Vitamin E & $\Rightarrow$ & \\
\hline \multirow[t]{2}{*}{ Agelaius phoeniceus } & \multirow[t]{2}{*}{$1-5$} & \multirow[t]{2}{*}{ Yolk } & Carotenoids & y & \multirow[t]{2}{*}{ Royle et al. (2011), Newbrey et al. (2015) } \\
\hline & & & Vitamin E & ע & \\
\hline $\begin{array}{l}\text { Xanthocephalus } \\
\text { xanthocephalus }\end{array}$ & $1-5$ & Yolk & Carotenoids & עי די & Newbrey et al. (2008) \\
\hline Hirundo rustica & $1-6$ & Yolk & Carotenoids & y & Saino et al. (2002), Safran et al. (2008) \\
\hline \multirow[t]{4}{*}{ Larus michahellis } & \multirow[t]{4}{*}{$1-3$} & \multirow[t]{4}{*}{ Yolk } & Carotenoids & $y$ & \multirow[t]{4}{*}{ Rubolini et al. (2011), Parolini et al. (2015) } \\
\hline & & & Vitamin E & $y$ & \\
\hline & & & OXY & $\Rightarrow$ & \\
\hline & & & Total OXY & ע & \\
\hline \multirow[t]{2}{*}{ Larus fuscus } & \multirow[t]{2}{*}{$1-3$} & \multirow[t]{2}{*}{ Yolk } & Carotenoids & $y$ & \multirow[t]{2}{*}{ Royle et al. (1999, 2001), Verboven et al. (2005) } \\
\hline & & & Vitamin E & $y$ & \\
\hline \multirow[t]{2}{*}{ Larus audouinii } & \multirow[t]{2}{*}{$1-3$} & Albumen & OXY & ע & \multirow[t]{2}{*}{ García-Tarrasón et al. (2014) } \\
\hline & & Yolk & OXY & y & \\
\hline \multirow[t]{2}{*}{ Larus ridibundus } & \multirow[t]{2}{*}{$1-3$} & \multirow[t]{2}{*}{ Yolk } & Carotenoids & $y$ & \multirow[t]{2}{*}{ Groothuis et al. (2006) } \\
\hline & & & Vitamin E & $y$ & \\
\hline \multirow[t]{2}{*}{ Eudyptes chrysocome } & $1-2$ & Albumen & OXY/Total OXY & $\Rightarrow / \pi$ & This study \\
\hline & & Yolk & $\mathrm{OXY} /$ Total OXY & $\Rightarrow / \pi$ & \\
\hline
\end{tabular}

Neither OXY Female nor ROM Female values at A-egg laying were affected by the total amount of antioxidants that females had already deposited in their clutch $\left(F_{1,36}=0.081, p=0.778\right.$ for $\mathrm{OXY}_{\text {Female }}$ and $F_{1,36}=$ $0.791, p=0.380$ for $\mathrm{ROM}_{\text {Female }}$ ).

\subsection{Egg isotopic composition}

The isotope values of females were strongly and positively correlated with the isotope values of their two eggs, both for $\delta^{13} \mathrm{C}$ and $\delta^{15} \mathrm{~N}$, and

\section{Female}

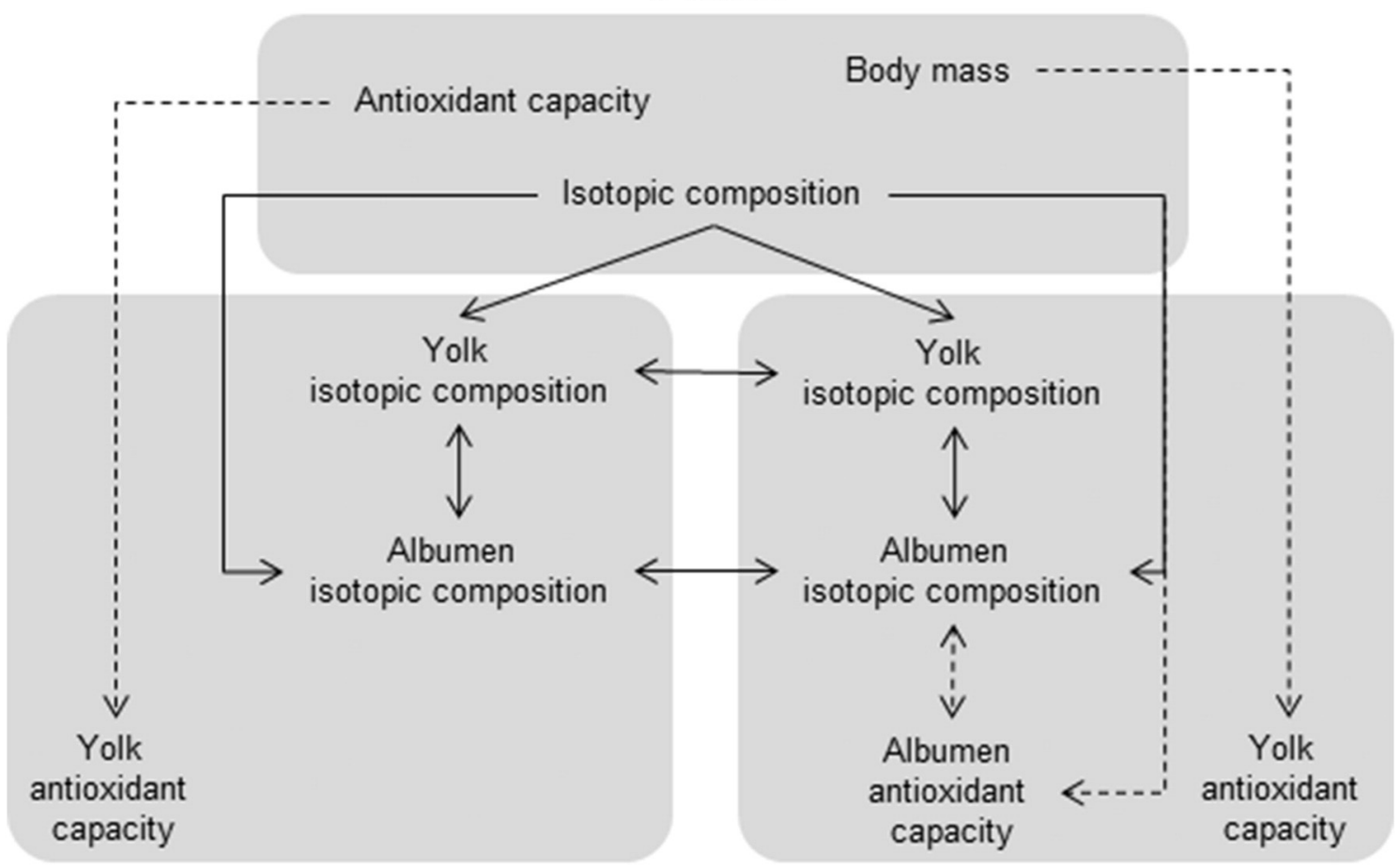

A-egg

B-egg

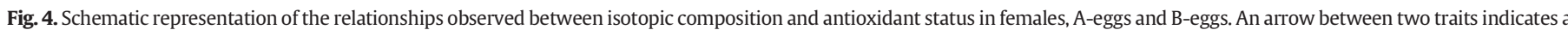
significant association $(p<0.05)$. Solid arrows show positive relationships while dashed arrows show negative relationships between and within the three compartments. 
both in the yolk and in the albumen (all $r>0.823, p<0.001$ ). Accordingly, isotope values were significantly positively correlated between eggs within clutches (Table 1), and between albumen and yolk within eggs (Table 2). This led to identical $\delta^{13} C_{\text {Yolk }}$ in A- and B-eggs (Table 1; Fig. 3). However, $\delta^{13} \mathrm{C}_{\text {Albumen }}, \delta^{15} \mathrm{~N}_{\text {Yolk }}$ and $\delta^{15} \mathrm{~N}_{\text {Albumen }}$ were significantly higher in B-eggs than in A-eggs (Table 1; Fig. 3), although these differences were very small (on average $\leq 0.2 \%$ ).

\subsection{Intra-clutch difference}

The intra-clutch difference in mass and in antioxidant capacity did not relate to any of the variables we tested (Table 4). Nevertheless, we observed a link between female isotopic composition and the intraclutch difference in isotopic composition (Table 4): B-eggs presented lower $\delta^{15} \mathrm{~N}_{\text {Yolk }}$ than A-eggs in females with low isotope values, while they had higher $\delta^{15} \mathrm{~N}_{\text {Yolk }}$ than A-eggs in females with high isotope values (Fig. 2c).

\section{Discussion}

\subsection{Intra-clutch difference in oxidative levels}

Based on the fact that embryonic growth rate and yolk antioxidant concentration covary in birds (Deeming and Pike, 2013; Parolini et al., 2015), we suspected that higher antioxidant levels in B-eggs compared to A-eggs may partly explain why B-eggs are less sensitive to incubation conditions than A-eggs, and the shorter incubation duration of B-eggs compared to A-eggs observed in crested penguin (Prediction 1). We partly confirmed this first prediction since B-eggs had higher Total OXY values than A-eggs (for yolk, albumen and whole egg). However, we did not find any difference in OXY values between A- and B-eggs (again for yolk and albumen). These results suggest that the antioxidants are transferred from females to both eggs at the same rate. The fact that females could maintain the same antioxidant transfer to Beggs even though they had already allocated antioxidant resources to A-eggs may be related to specific features of crested penguins. The clutch only comprises two eggs and is small in terms of mass, and therefore also small in terms of resources to allocate relative to females' mass. Indeed, in smaller bird species with relatively larger clutches (e.g. passerines), antioxidant transfer usually decreases only in the last egg(s) (see Table 5).

As B-eggs are heavier than A-eggs in southern rockhopper penguins, the intra-clutch difference in the total quantity of antioxidants that we observed is solely due to the difference in mass between the two eggs, (see Table 1). Thus, while females favour B-eggs over A-eggs in terms of egg mass, we could not show this directly for antioxidants per se. Consequently, the shorter incubation duration of B-eggs compared to Aeggs is unlikely to be linked to low antioxidant levels.

\subsection{Female oxidative status and body mass}

The influence of female traits on the oxidative status of their eggs varied between egg components, and between A- and B-eggs. Females with high antioxidant defences laid A-eggs with lower $\mathrm{OXY}_{\mathrm{Yolk}}$, and heavy females laid B-eggs with lower $\mathrm{OXY}_{\text {Yolk. These results suggest }}$ that female condition influences yolk antioxidant status. Nevertheless, the direction of these relationships is opposite to our predictions (Prediction 2). One explanation might be that the transfer of resources to the yolk deprives females of resources (antioxidant resources for Aeggs, other resources for B-egg). If this holds true, the small size of Aeggs may represent a strategy for females to spare their own antioxidant defences during the egg laying period. However, as our data are only correlative and only reflect a given time point, such interpretation remains for the moment speculative. Further studies measuring the antioxidant status of females over the whole egg-laying sequence are necessary to examine whether egg laying really deprives females of particular resources.

\subsection{Isotopic composition}

All measured isotope values were strongly correlated between female red blood cells, eggs and egg components (see Fig. 4), suggesting that the diet of females determined egg isotopic composition (Prediction 2). Accordingly, the intra-clutch differences between A- and Beggs were not significant for $\delta^{13} C_{\text {Yolk }}$ and small $(\leq 0.2 \%$ ) but significant for $\delta^{13} \mathrm{C}_{\text {Albumen, }} \delta^{15} \mathrm{~N}_{\text {Yolk }}$ and $\delta^{15} \mathrm{~N}_{\text {Albumen }}$ (Prediction 3). While these differences might reflect minor differences in resource allocation between A- and B-eggs, they were within the range of the analytical precision and their biological relevance is therefore questionable.

Interestingly, we found that differences in terms of isotopic composition between the yolk of A- and B-eggs were more pronounced when female isotope values were high (Fig. 2c). High isotope values in females could indicate a lower contribution of krill in their diet, as krill is characterized by low $\delta^{13} \mathrm{C}$ and $\delta^{15} \mathrm{~N}$ values compared to other known prey consumed by rockhopper penguins (such as fish) (Polito et al., 2011; Dehnhard et al., 2016). Even though the underlying mechanisms remain unclear, this shows that female diet affects eggs differentially at least for isotopic compositions (Prediction 4), and that females with a low contribution of krill in their diet differentiate resources more strongly between A- and B-yolks.

\subsection{Relationship between oxidative status and isotopic composition}

We did not find any relationship between isotopic composition and antioxidant capacities in females or in yolks. Importantly, this absence of relationship in yolks was not due to their delipidation before isotopic analyses (which is likely to have removed lipophilic antioxidant compounds), as similar results were observed with or without delipidation. One reason explaining why we did not find any relationship in adult penguins (as in previous studies; Beaulieu et al., 2015) may be that we measured these parameters in different tissues (red blood cells and plasma, respectively). Red blood cells have a slower turn-over rate than plasma, and therefore their isotopic composition reflects resource use / diet over several weeks (see Thiebot et al., 2015), whereas the antioxidant capacity measured from plasma samples reflects a shorter period of time. Other reasons explaining the absence of a relationship between isotopic composition and antioxidant defences may be that antioxidant compounds in females and in eggs come from a group of prey items that are not isotopically distinguishable, or that different prey with similar isotopic compositions contribute differently to antioxidant defences.

Despite these potential limitations, we still found a negative relationship between females' isotopic composition and $\mathrm{OXY}_{\text {Albumen }}$ values in B-eggs. This suggests that some compounds with low isotope values transferred from females to B-eggs still contributed to the antioxidant capacity of the albumen in B-eggs, and that the consumption of krill (with low isotope values) during migration (when red blood cells were synthesized) can have postponed effects on the antioxidant defences of B-eggs.

Why such a relationship was only detected in B-eggs and not in Aeggs remains, however, unclear.

\section{Conclusion}

Overall, we found only little evidence that the extreme intra-clutch egg size dimorphism in southern rockhopper penguins is coupled with antioxidant and isotopic differences. Differences in antioxidant status within clutches appear unlikely to underlie a distinction in sensitivity to incubation conditions between eggs. Such differential allocation of antioxidants might be unnecessary in this species, as females control overall resource allocation to eggs by regulating their mass and by 
creating a strong mass dimorphism among eggs. Therefore, differential allocation of antioxidants among eggs may be more likely to occur in species where egg mass dimorphism is not as strong as in southern rockhopper penguins, and where compositional differences among eggs may be relatively more important for determining chick survival.

\section{Acknowledgements}

We are grateful to the New Island Conservation Trust for permission to work on the island and for logistic support. We wish to thank Ian, Maria and Georgina Strange for their support during the field seasons. Thanks also to Nick Rendell and the Falkland Islands Government for their logistical help. All applicable institutional and/or national guidelines for the care and use of animals were followed. The study was performed according to Belgian and Flemish law and was approved by the ethical committee on animal experimentation ECD [licence numbers 2011/44, 2013/29). All work was conducted under research licenses granted by the Environmental Planning Department of the Falkland Islands Government [research license numbers R16/2007, R06/2009]. This article does not contain any studies with human participants performed by any of the authors. The manuscript benefited from critical comments by David Carslake. This work was supported by the University of Antwerp and by the Research Fund - Flanders FWO [grant numbers 1.2.619.10.N.00, 1.5.020.11.N.00] to MP as a postdoctoral fellow. GL and NS are both appointed at the Belgian National Fund for Scientific Research (FRS-FNRS).

\section{References}

Ancel, A., Beaulieu, M., Gilbert, C., 2013. The different breeding strategies of penguins: a review. C. R. Biol. 336, 1-12.

Beaulieu, M., Ropert-Coudert, Y., Le Maho, Y., Ancel, A., Criscuolo, F., 2010a. Foraging in an oxidative environment: relationship between $\delta^{13} \mathrm{C}$ values and oxidative status in Adélie penguins. Proc. R. Soc. Lond. B 227, 1087-1092.

Beaulieu, M., Spée, M., Lazin, D., Ropert-Coudert, Y., Le Maho, Y., Ancel, A., Raclot, T., 2010b. Ecophysiological response of Adélie penguins facing an experimental increase in breeding constraints. J. Exp. Biol. 213, 33-39.

Beaulieu, M., González-Acuña, D., Thierry, A.-M., Polito, M.J., 2015. Relationships between isotopic values and oxidative status: insights from populations of gentoo penguins. Oecologia 177, 1211-1220.

Bonisoli Alquati, A., Rubolini, D., Romano, M., Boncoraglio, G., Fasola, M., Saino, N., 2007. Effects of egg albumen removal on yellow-legged gull chick phenotype. Funct. Ecol. $21,310-316$

Cherel, Y., Hobson, K.A., Bailleul, F., Groscolas, R., 2005. Nutrition, physiology, and stable isotopes: new information from fasting and molting penguins. Ecology 86, 2881-2888.

Cherel, Y., Hobson, K.A., Guinet, C., Vanpe, C., 2007. Stable isotopes document seasonal changes in trophic niches and winter foraging individual specialization in diving predators from the Southern Ocean. J. Anim. Ecol. 76, 826-836.

Coplen, T.B., 2011. Guidelines and recommended terms for expression of stable-isotoperatio and gas-ratio measurement results. Rapid Commun. Mass Spectrom. 25, 2538-2560.

Costantini, D., 2010. Complex trade-offs in the pigeon (Columba livia): egg antioxidant capacity and female serum oxidative status in relation to diet quality. J. Comp. Physiol. B - Biochem. Syst. Environ. Physiol. 180, 731-739.

Costantini, D., 2016. Oxidative stress ecology and the d-ROMs test: facts, misfacts and an appraisal of a decade's work. Behav. Ecol. Sociobiol. 70, 809-820.

Crossin, G.T., Trathan, P.N., Phillips, R.A., Dawson, A., Le Bouard, F., Williams, T.D., 2010. A carryover effect of migration underlies individual variation in reproductive readiness and extreme egg size dimorphism in macaroni penguins. Am. Nat. 176, 357-366.

Cucco, M., Guasco, B., Malacarne, G., Ottonelli, R., 2007. Effects of $\beta$-carotene on adult immune condition and antibacterial activity in the eggs of the grey partridge, Perdix perdix. Comp. Biochem. Physiol. A Mol. Integr. Physiol. 147, 1038-1046.

Deeming, D.C., Pike, T.W., 2013. Embryonic growth and antioxidant provision in avian eggs. Biol. Lett. 9 (6):20130757. http://dx.doi.org/10.1098/rsbl.2013.0757.

Dehnhard, N., Ludynia, K., Masello, J.F., Voigt, C.C., McGill, R.A.R., Quillfeldt, P., 2016. Plasticity in foraging behaviour and diet buffers effects of interannual environmental differences on chick growth and survival in southern rockhopper penguins Eudyptes chrysocome chrysocome. Polar Biol. 39, 1627-1641.

Demongin, L., Poisbleau, M., Raya Rey, A., Schiavini, A., Quillfeldt, P., Eens, M., Strange, I.J., 2010. Geographical variation in egg size dimorphism in rockhopper penguins. Polar Biol. 33, 469-476.

Ehrich, D., Tarroux, A., Stien, J., Lecomte, N., Killengreen, S., Berteaux, D., Yoccoz, N.G., 2011. Stable isotope analysis: modelling lipid normalization for muscle and eggs from arctic mammals and birds. Methods Ecol. Evol. 2, 66-76.

Ferrari, R.P., Martinelli, R., Saino, N., 2006. Differential effects of egg albumen content on barn swallow nestlings in relation to hatch order. J. Evol. Biol. 19, 981-993.
García-Tarrasón, M., Sanpera, C., Jover, L., Costantini, D., 2014. Levels of antioxidants in breeding female Audouin's gulls and their deposition in eggs across different environments. J. Exp. Mar. Biol. Ecol. 453, 116-122.

Gauthier, G., Bêty, J., Hobson, K.A., 2003. Are greater snow geese capital breeders? New evidence from a stable-isotope model. Ecology 84, 3250-3264.

Giordano, M., Costantini, D., Pick, J.L., Tschirren, B., 2015. Female oxidative status, egg antioxidant protection and eggshell pigmentation: a supplemental feeding experiment in great tits. Behav. Ecol. Sociobiol. 69, 777-785.

Grau, C.R., 1982. Egg formation in Fiordland crested penguins (Eudyptes pachyrhynchus). Condor 84, 172-177.

Griffith, S.C., Pariser, E.C., Tschirren, B., Astheimer, L.B., 2011. Resource allocation across the egg laying sequence in the wild zebra finch Taeniopygia guttata. J. Avian Biol. 42, 480-484.

Groothuis, T.G.G., Eising, C.M., Blount, J.D., Surai, P., Apanius, V., Dijkstra, C., Müller, W., 2006. Multiple pathways of maternal effects in black-headed gull eggs: constraint and adaptive compensatory adjustment. J. Evol. Biol. 19, 1304-1313.

Hackl, R., Bromundt, V., Daisley, J., Kotrschal, K., Möstl, E., 2003. Distribution and origin of steroid hormones in the yolk of Japanese quail eggs (Coturnix coturnix japonica). J. Comp. Physiol. B - Biochem. Syst. Environ. Physiol. 173, 327-331.

Hargitai, R., Matus, Z., Hegyi, G., Michl, G., Tóth, G., Török, J., 2006. Antioxidants in the egg yolk of a wild passerine: differences between breeding seasons. Comp. Biochem. Physiol. B Biochem. Mol. Biol. 143, 145-152.

Hipfner, J.M., Dale, J., McGraw, K.J., 2010. Yolk carotenoids and stable isotopes reveal links among environment, foraging behavior and seabird breeding success. Oecologia 163 351-360.

Hobson, K.A., Jaatinen, K., Öst, M., 2015. Differential contributions of endogenous and exogenous nutrients to egg components in wild Baltic Common Eiders (Somateria mollissima): a test of alternative stable isotope approaches. Auk 132, 624-633.

Hõrak, P., Surai, P.F., Møller, A.P., 2002. Fat-soluble antioxidants in the eggs of great tits Parus major in relation to breeding habitat and laying sequence. Avian Sci. 2, 123-130.

Isaksson, C., Johansson, A., Andersson, S., 2008. Egg yolk carotenoids in relation to habitat and reproductive investment in the great tit Parus major. Physiol. Biochem. Zool. 81, $112-118$.

Jönsson, K.I., 1997. Capital and income breeding as alternative tactics of resource use in reproduction. Oikos 78, 57-66.

Lipar, J.L., Ketterson, E.D., Nolan Jr., V., Casto, J.M., 1999. Egg yolk layers vary in the concentration of steroid hormones in two avian species. Gen. Comp. Endocrinol. 115, 220-227.

Meijer, T., Drent, R., 1999. Re-examination of the capital and income dichotomy in breeding birds. Ibis 141, 399-414.

Møller, A.P., Karadas, F., Mousseau, T.A., 2008. Antioxidants in eggs of great tits Parus major from Chernobyl and hatching success. J. Comp. Physiol. B - Biochem. Syst. Environ. Physiol. 178, 735-743.

Morales, J., Velando, A., Moreno, J., 2008. Pigment allocation to eggs decreases plasma antioxidants in a songbird. Behav. Ecol. Sociobiol. 63, 227-233.

Navara, K.J., Badyaev, A.V., Mendonça, M.T., Hill, G.E., 2006. Yolk antioxidants vary with male attractiveness and female condition in the house finch (Carpodacus mexicanus). Physiol. Biochem. Zool. 79, 1098-1105.

Newbrey, J.L., Reed, W.L., Foster, S.P., Zander, G.L., 2008. Laying-sequence variation in yolk carotenoid concentrations in eggs of yellow-headed blackbirds (Xanthocephalus xanthocephalus). Auk 125, 124-130.

Newbrey, J.L., Paszkowski, C.A., McGraw, K.J., Ogle, S., 2015. Laying-sequence variation in yolk carotenoids and egg characteristics in the red-winged blackbird Agelaius phoeniceus. J. Avian Biol. 46, 46-54.

Oppel, S., Federer, R.N., O'Brien, D.M., Powell, A.N., Hollmén, T.E., 2010. Effects of lipid extraction on stable isotope ratios in avian egg yolk: is arithmetic correction a reliable alternative? Auk 127, 72-78.

Pariser, E.C., Gilbert, L., Hazon, N., Arnold, K.E., Graves, J.A., 2012. Mind the gap: the ratio of yolk androgens and antioxidants varies between sons and daughters dependent on paternal attractiveness. Behav. Ecol. Sociobiol. 66, 519-527.

Parolini, M., Romano, M., Caprioli, M., Rubolini, D., Saino, N., 2015. Vitamin E deficiency in last-laid eggs limits growth of yellow-legged gull chicks. Funct. Ecol. 29, 1070-1077.

Poisbleau, M., Demongin, L., Strange, I.J., Otley, H., Quillfeldt, P., 2008. Aspects of the breeding biology of the southern rockhopper penguin Eudyptes c. chrysocome and new consideration on the intrinsic capacity of the A-egg. Polar Biol. 31, 925-932.

Poisbleau, M., Demongin, L., Trouve, C., Quillfeldt, P., 2009. Maternal deposition of yolk corticosterone in clutches of southern rockhopper penguins (Eudyptes chrysocome chrysocome). Horm. Behav. 55, 500-506.

Poisbleau, M., Demongin, L., van Noordwijk, H.J., Strange, I.J., Quillfeldt, P., 2010. Sexual dimorphism and use of morphological measurements to sex adults, immatures and chicks of rockhopper penguins. Ardea 98, 217-224.

Poisbleau, M., Demongin, L., Parenteau, C., Eens, M., 2011a. Intra-clutch ratio of yolk progesterone level changes with laying date in rockhopper penguins: a strategy to influence brood reduction? PLoS One 6 (11), e27765. http://dx.doi.org/10.1371/journal. pone.0027765.

Poisbleau, M., Demongin, L., Chastel, O., Eens, M., Quillfeldt, P., 2011b. Yolk androgen deposition in rockhopper penguins, a species with reversed hatching asynchrony. Gen. Comp. Endocrinol. 170, 622-628.

Poisbleau, M., Carslake, D., Demongin, L., Eens, M., Chastel, O., Quillfeldt, P., 2011c. Yolk androgen deposition without an energetic cost for female rockhopper penguins: a compensatory strategy to accelerate brood reduction? Biol. Lett. 7, 605-607.

Poisbleau, M., Dehnhard, N., Demongin, L., Quillfeldt, P., Eens, M., 2015. Two eggs, two different constraints: a potential explanation for the puzzling intraclutch egg size dimorphism in Eudyptes penguins. Ecol. Evol. 5, 2827-2838.

Polito, M.J., Trivelpiece, W.Z., Karnovsky, N.J., Ng. E., Patterson, W.P., Emslie, S.D., 2011. Integrating stomach content and stable isotope analyses to quantify the diets of 
pygoscelid penguins. PLoS One 6 (10), e26642. http://dx.doi.org/10.1371/journal. pone.0026642.

Ramírez, F., Forero, M.G., Hobson, K.A., Chiaradia, A., 2015. Older female little penguins Eudyptula minor adjust nutrient allocations to both eggs. J. Exp. Mar. Biol. Ecol. 468, 91-96.

Roff, D.A., 1992. The Evolution of Life Histories: Theory and Analysis. Chapman \& Hall, New York, NY.

Royle, N.J., Surai, P.F., McCartney, R.J., Speake, B.K., 1999. Parental investment and egg yolk lipid composition in gulls. Funct. Ecol. 13, 298-306.

Royle, N.J., Surai, P.F., Hartley, I.R., 2001. Maternally derived androgens and antioxidants in bird eggs: complementary but opposing effects? Behav. Ecol. 12, 381-385.

Royle, N.J., Surai, P.F., Hartley, I.R., 2003. The effect of variation in dietary intake on maternal deposition of antioxidants in zebra finch eggs. Funct. Ecol. 17, 472-481.

Royle, N.J., Hall, M.E., Blount, J.D., Forbes, S., 2011. Patterns of egg yolk antioxidant co-variation in an avian brood parasite-host system. Behav. Ecol. Sociobiol. 65, 313-323.

Rubolini, D., Romano, M., Navara, K.J., Karadas, F., Ambrosini, R., Caprioli, M., Saino, N., 2011. Maternal effects mediated by egg quality in the yellow-legged gull Larus michahellis in relation to laying order and embryo sex. Front. Zool. 8:24. http://dx. doi.org/10.1186/1742-9994-8-24.

Safran, R.J., Pilz, K.M., McGraw, K.J., Correa, S.M., Schwabl, H., 2008. Are yolk androgens and carotenoids in barn swallow eggs related to parental quality? Behav. Ecol. Sociobiol. 62, 427-438.

Saino, N., Bertacche, V., Ferrari, R.P., Martinelli, R., Møller, A.P., Stradi, R., 2002. Carotenoid concentration in barn swallow eggs is influenced by laying order, maternal infection and paternal ornamentation. Proc. R. Soc. Lond. B 269, 1729-1733.

Schamber, J.L., Esler, D., Flint, P.L., 2009. Evaluating the validity of using unverified indices of body condition. J. Avian Biol. 40, 49-56.
St. Clair, C.C., 1996. Multiple mechanisms of reversed hatching asynchrony in rockhopper penguins. J. Anim. Ecol. 65, 485-494.

Stearns, S.C., 1992. The Evolution of Life Histories. Oxford University Press, Oxford.

Thiebot, J.-B., Bost, C.-A., Dehnhard, N., Demongin, L., Eens, M., Lepoint, G., Cherel, Y., Poisbleau, M., 2015. Mates but not sexes differ in migratory niche in a monogamous penguin species. Biol. Lett. 11:20150429. http://dx.doi.org/10.1098/rsbl.2015.0429.

Török, J., Hargitai, R., Hegyi, G., Matus, Z., Michl, G., Péczely, P., Rosivall, B., Tóth, G., 2007. Carotenoids in the egg yolks of collared flycatchers (Ficedula albicollis) in relation to parental quality, environmental factors and laying order. Behav. Ecol. Sociobiol. 61, 541-550.

Tou, J.C., Jaczynski, J., Chen, Y.C., 2007. Krill for human consumption: nutritional value and potential health benefits. Nutr. Rev. 65, 63-77.

Verboven, N., Evans, N.P., D'Alba, L., Nager, R.G., Blount, J.D., Surai, P.F., Monaghan, P., 2005. Intra-specific interactions influence egg composition in the lesser black-backed gull (Larus fuscus). Behav. Ecol. Sociobiol. 57, 357-365.

Warham, J., 1975. The crested penguins. In: Stonehouse, B. (Ed.), The Biology of Penguins. The Macmillan Press, London, UK, pp. 189-269.

Williams, T.D., 1995. The Penguins. Oxford University Press, Oxford, UK.

Williamson, K.A., Surai, P.F., Graves, J.A., 2006. Yolk antioxidants and mate attractiveness in the zebra finch. Funct. Ecol. 20, 354-359.

Wilson, H.R., 1997. Effects of maternal nutrition on hatchability. Poult. Sci. 76, 134-143.

Zera, A.J., Harshman, L.G., 2001. The physiology of life history trade-offs in animals. Annu. Rev. Ecol. Syst. 32, 95-126. 